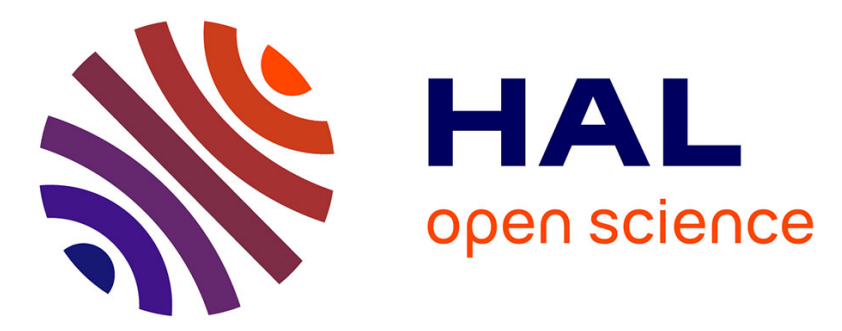

\title{
Integrating alum sludge with waste-activated sludge in co-conditioning and dewatering: a case study of a city in south France
}

Baiming Ren, Nathalie Lyczko, Yaqian Zhao, Ange Nzihou

\section{- To cite this version:}

Baiming Ren, Nathalie Lyczko, Yaqian Zhao, Ange Nzihou. Integrating alum sludge with wasteactivated sludge in co-conditioning and dewatering: a case study of a city in south France. Environmental Science and Pollution Research, 2020, 27, pp.14863 - 14871. 10.1007/s11356-020-08056-0 . hal-02483458

\section{HAL Id: hal-02483458 \\ https://imt-mines-albi.hal.science/hal-02483458}

Submitted on 31 Mar 2020

HAL is a multi-disciplinary open access archive for the deposit and dissemination of scientific research documents, whether they are published or not. The documents may come from teaching and research institutions in France or abroad, or from public or private research centers.
L'archive ouverte pluridisciplinaire HAL, est destinée au dépôt et à la diffusion de documents scientifiques de niveau recherche, publiés ou non, émanant des établissements d'enseignement et de recherche français ou étrangers, des laboratoires publics ou privés. 


\title{
Integrating alum sludge with waste-activated sludge in co-conditioning and dewatering: A case study of a city in south France
}

\author{
Baiming Ren ${ }^{1,2,3^{*}}$, Nathalie Lyczko ${ }^{1}$, Yaqian Zhao ${ }^{2,3}$, Ange Nzihou ${ }^{1}$ \\ ${ }^{1}$ Université de Toulouse, IMT Mines Albi, RAPSODEE CNRS UMR-5302, Jarlard, Albi 81013 \\ ${ }^{2}$ Centre for Water Resources Research, School of Civil Engineering, University College \\ Dublin,Belfield, Dublin 4, Ireland \\ ${ }^{3}$ State Key Laboratory of Eco-Hydraulics in Northwest Arid Region of China, Xi'an University \\ ofTechnology, Xi' an 710048, P.R. China
}

*Corresponding author E-mail: ren.baiming@ucdconnect.ie ORCID: 0000-0001-9656-1053

\begin{abstract}
The unique geographical location of waterworks and wastewater treatment plant (WWTP) in Graulhet (France) profited the environmental resource integration and "Circular Economy." Alum sludge from a local waterworks was introduced to co-conditioning and dewatering with waste-activated sludge from a nearby WWTP to examine the role of the alum sludge in improving the dewaterability of the mixed sludge. Experiments demonstrated that the optimal mixing ratio was 1:1 (waste-activated sludge/alum sludge, v/v). Alum sludge has been shown to beneficially enhance mixed sludge dewaterability, by decreasing both the specific resistance to filtration (SRF) and the capillary suction time (CST). Moreover, the optimal polymer (Sueprfloc-492HMW) dose for the mixed sludge (mix ratio 1:1) was 200mg/l, highlighting a huge savings (14 times) in polymer addition without alum sludge involvement. In addition, cost-effective analysis of its potential full-scale application has demonstrated that the initial investment could be returned in 11years. The co-conditioning and dewatering strategy can be viewed as a "win-win" strategy for the Graulhet, France water and wastewater industry.
\end{abstract}

Keywords: Alum sludge reuse, Circular Economy, Jar-test, Sewerage sludge, Technoeconomic analysis, Waterworks residues 


\section{Graphical Abstract}

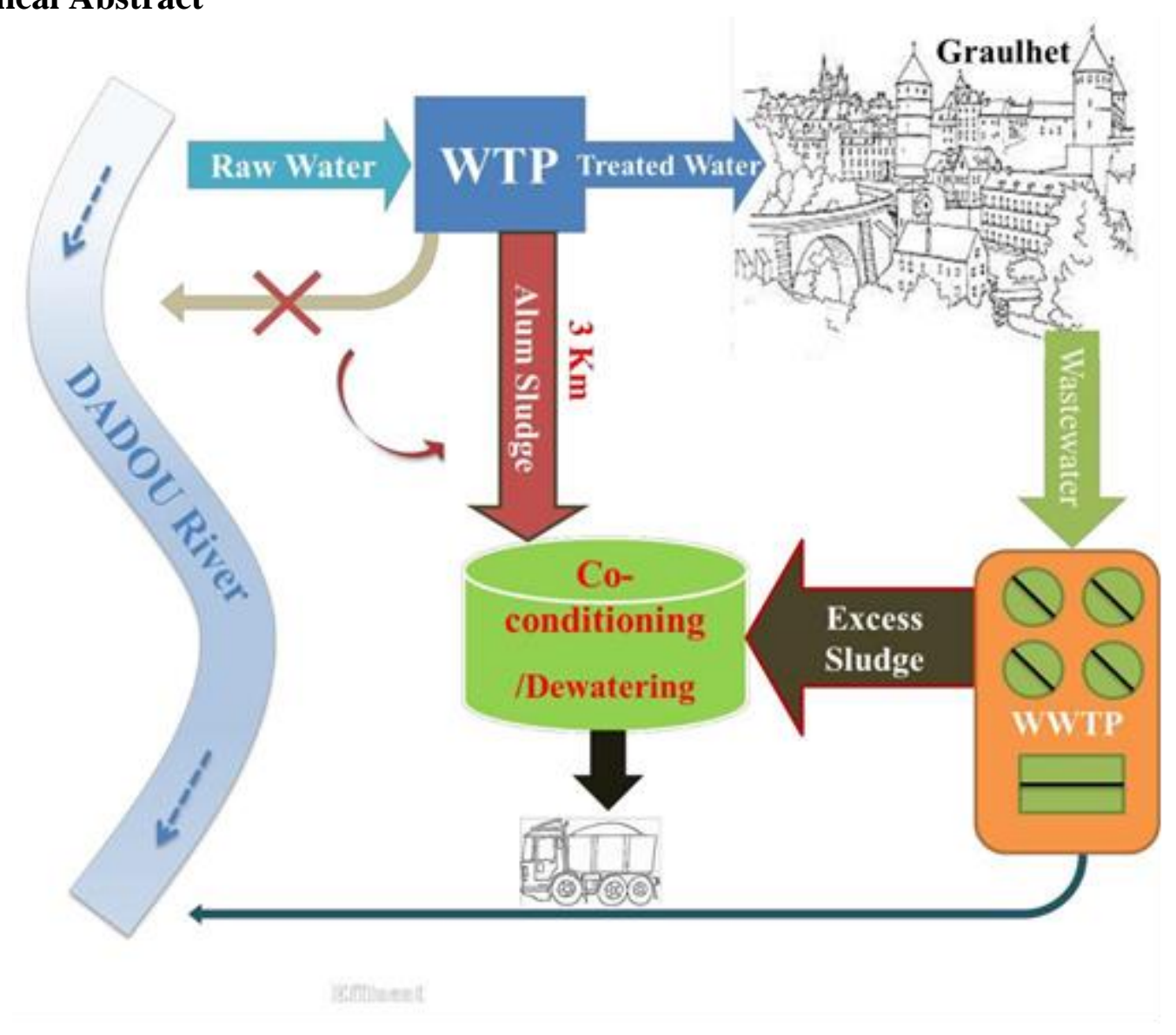

\section{Introduction}

Global expansion of urban areas and industrial development are often associated with substantial water demand that require intensive treatment of both water and wastewater. Large amount of sludges as inevitable by-product along with the water/wastewater purification process is generated worldwide (Zhao et al. 2018). In particular, the sewerage sludge's hydrophilic nature of extracellular polymeric substances (EPSs) binds water molecules to the solid surface and traps the water within sludge flocs, forming a high compressibility sludge matrix (Zhu et al. 2018). Water increases transportation and disposal costs. Thus, sludge dewatering is a vital step for reducing the sludge volume, being regarded as the most expensive and least understood process (Chang et al. 2001, Xiong et al. 2018). Accordingly, efficient sludge conditioning prior to mechanical dewatering is required. Various studies have been performed to enhance sludge dewatering recently, such as: 1) the magnetic field pretreatment 
combined with cationic polyacrylamide additive ( $\mathrm{Bi}$ et al. 2015); 2) polyaluminum chloride (PACl) co-conditioning with two linear polyelectrolytes (Pambou et al. 2016); 3) the combination of ultrasound-cationic polyacrylamide-rice husk to sludge conditioning (Zhu et al. 2018); and 4) a combined coagulation-flocculation process using $\mathrm{PACl}$ and a biopolymer harvested from anaerobically digested swine wastewater (Guo et al. 2018). Additionally, Wei et al. (2018) have reviewed the updated process of coagulation/flocculation using different coagulants/flocculants and their combinations with other pretreatments with massive information on this area. Practical operations indicate that dewatering performance for waste activated sludge is still relatively poor (Qi et al. 2011a). In particular, extra energy requirements as well as the highly complicated and multilevel structural features among these aforementioned approaches seem to hinder their performance in WWTPs sludge dewatering.

Alum sludge, a kind of waterworks residues when aluminum sulfate was used for the raw water purification, can be easily obtained from local waterworks either in liquid phase or in solid phase (after dewatering) (Wang et al. 2018). Historically, the waterworks residues were discharged directly to nearby natural water bodies without any further treatment or reuse. However, regulations implemented in many places have now made these disposal methods forbidden due to the negative environmental impacts, such as the heavy metal contained in the waterworks residues (Mazari et al. 2018). Therefore, the prevalence of mechanically dewatering of waterworks residues to sludge cakes in most places worldwide could significantly reduce its volume for final disposal. Unfortunately, landfilling of waterworks residues has indeed been the most famous applied method over the world, as the valuable elements/materials contained in the waterworks residues didn't have any kind of recycle or reuse (Yang et al. 2018). Nowadays, transforming the waterworks residues as a useful material, rather than a waste for landfill has drawn universal attention while the beneficial reuse of alum sludge becomes an overwhelming superiority in researchers and engineers for the last decade, as alum sludge accounts for the majority of the waterworks residues over the world (Ren et al. 2019).

Four major routes which include eleven possible ways of reusing alum sludge, such as the use in wastewater treatment process, use as building/construction materials, the use in landbased application and the recovery of the coagulant (Ahmad et al. 2016), had been developed and recognized in the last decades. In fact, only few studies investigated alum sludge coconditioning and dewatering with sewage sludge to improve the sewage sludge dewaterability. For example, Lai and Liu (2004) indicated that alum sludge may act as a skeleton builder in mixed sludge and thus has a beneficial dewatering process effect. Yang et al. (2007, 2009) 
examined the role of alum sludge in improving sewerage sludge dewaterability. Their results demonstrated that an optimal mixed ratio of 2:1 (anaerobic digested sludge:alum sludge, in the on volume basis) could improve the resultant sludge dewaterability and could cause about 99 $\%$ reduction in phosphorus loading in the reject water. Moreover, the optimal polymer (Superfloc C2260) dosage required for conditioning was also reduced to $15 \mathrm{mg} / \mathrm{L}$ (in the mixed sludge) from $120 \mathrm{mg} / \mathrm{L}$ (blank), thus providing cost savings in polymer addition. However, considering the co-conditioning practice, alum sludge transport and haul distance (50 km away) between treatment facilities in Dublin, Ireland, these made the benefits of co-conditioning and dewatering and related economics unrealistic.

In contrast, the WWTP of Graulhet, France, is uniquely located $3 \mathrm{~km}$ away from the waterworks. Co-conditioning of the sludges generated from these two plants seems realistic. The Graulhet WWTP employs a conventional biological treatment process with the capacity of $11000 \mathrm{~m} 3 /$ day, while the waterworks produces $2200 \mathrm{~m} 3$ drinking water per day. Currently, the liquid alum sludge was directly drained into the Dadou river. Significantly, these two plants are operated by the same company (Régie Municipale de l'Eaux et de l'Assainissement de Graulhet). This provides an opportunity of co-conditioning the sewerage sludge with alum sludge in order to achieve sustainable development and reuse regarding sludge management of using "waste," i.e., alum sludge, for sewage sludge treatment, i.e., used as "conditioner." Therefore, a scientific investigation was needed to promote its application by examining the feasibility of co-conditioning sewerage sludge with liquid alum sludge in Graulhet, France. It is expected that this study forms the main technical issues of the co-conditioning and thus forms the basis of further investigation towards co-conditioning and dewatering of sewage sludge with alum sludge practice in Graulhet, France.

\section{Materials and Methods}

\section{Materials}

Liquid alum sludge with moisture content of $99.43 \%$ was obtained from the settling tank of the treatment plant, located upstream of Graulhet right bank, where aluminum sulfate is used as coagulant for treating river water. The sewerage sludge (or excess/waste-activated sludge) with an average water content of $96.46 \%$ was obtained from the bottom of a secondary clarifier at the Graulhet WWTP. Currently, the Graulhet WWTP used the cationic polymer Sueprfloc-492HMW (Kemira, Finland), which was granular powder and 
off-white in appearance with a molecular weight of 10,000,000, bulk density of $0.75 \mathrm{~kg} / \mathrm{l}$ and $\mathrm{pH}$ of 3-5 for $0.5 \%$ solution $\left(25^{\circ} \mathrm{C}\right)$, for sludge conditioning before mechanical dewatering using a belt press filter. Polymer Sueprfloc-492HMW was also collected from the Graulhet WWTP.

\section{Co-conditioning procedure}

The conditioning tests were performed at room temperature using a four paddles standard jarstirring apparatus, where blended sludge samples of $600 \mathrm{~mL}$ in $1000 \mathrm{~mL}$ beakers were used in the experiments. Alum sludge and waste-activated sludge were mixed at different volume ratios (2:1, 1:1, 1:2, 1:3 and 1:4). The optimized mixing ratio (alum sludge: waste-activated sludge, $\mathrm{v} / \mathrm{v}$ ) was determined by considering the daily quantity of alum sludge generated from Graulhet WTP as well as the mixed sludge dewaterability.

Thereafter, the dosage range based on the literature (Yang et al. 2007, 2009) (from 10 to $400 \mathrm{mg} / 1,10,50$ to $400 \mathrm{mg} / 1$, at increments of $50 \mathrm{mg} / \mathrm{l}$ ) of the polymer Sueprfloc-492HMW was added as chemical conditioner to the optimized mixing ratio to achieve the optimal polymer dosage. This procedure was also performed using the jar-stirring apparatus, where the sludge and various polymer doses were fast mixing at $200 \mathrm{rpm}$ (a mean velocity gradient (G) value of $330 \mathrm{~s}-1$ ) for $30 \mathrm{~s}$, and then slowly mixing at $60 \mathrm{rpm}$ (at a G value of $34 \mathrm{~s}-1$ ) for $300 \mathrm{~s}$. This provides a GT value of 10000 , which is considered as the most critical determinant factor to ensure the shear conditions. In the end, the dewaterability of the resultant sludge was evaluated using capillary suction time (CST) and specific resistance to filtration (SRF) following the standard procedure. All those processes (e.g., co-conditioning, polymer dosage, and measuring CST and SRF) have been repeated by three parallel experiments. The standard deviation was also calculated.

CST (s) is a measure of the readiness with which a sludge sample "releases" its water. The sample is placed in a reservoir above a sheet of chromatography paper, and the time taken for the liquid to be drawn to a certain radial distance by capillary action is measured. Much of the appeal of the method lies in its speed, simplicity, and need for only small volumes (Lai and Liu 2004).

$\mathrm{SRF}(\mathrm{m} / \mathrm{kg})$ is a kinetic parameter of a unit mass of sludge per unit area of filter, which could be obtained from the following equations:

$S R F=\frac{\Delta P}{\emptyset_{0} \rho_{S} \eta_{L} v} \frac{d t}{d v}$ 
Where, $\Delta P$ is the applied pressure, $\phi_{0}$ is the bulk or initial porosity, $\rho_{s}$ is the density of sludge, $v \quad$ is the specific filtrate volume (volume per unit superficial cross-sectional flow area) and $\eta_{\mathrm{L}}$ is the liquid viscosity (Yang et al. 2007).

Further, the adjustment to the SRF measurement with the intention of removing of filterpore blocking occurs at high excess polymer doses (Chang et al. 2001; Zhu et al. 2018). The methods can be described as the following equation:

$\frac{d v}{d t}=\frac{\Delta P}{\eta_{L}\left(\alpha_{m} C_{v}+r_{m}\right)}$

Where, $\mathrm{C}$ is the mass of dry solids per volume of filtrate, $\mathrm{rm}$ is a resistance due to the membrane (and drainage system), and $\alpha \mathrm{m}$ is the cake specific resistance, based upon mass of solids in cake (per unit area).

\section{Characterization and analyses}

To examine the elements in the solid phase and supernatant of the sludge, a laboratory-model centrifuge (Sigma 2K15, Germany) was operated at $8000 \mathrm{r} / \mathrm{min}$ to separate the sludge. The solids were then washed with distilled water three times. Next, the solids were dried at $105^{\circ} \mathrm{C}$ for $24 \mathrm{~h}$. The solid element content was tested by inductively coupled plasma-atomic emission spectroscopy (ICP-AES), and by CHNS analysis using a Thermoquest NA2100. Scanning electron microscopy (SEM) (Philips XL30 ESEM apparatus; FEI Company) coupled with an energy-dispersive X-ray spectroscopy (EDX analysis), was used to observe the sludge samples before and after dewatering.

The sludge dewaterability before and after co-conditioning was evaluated using the CST apparatus and SRF facility. A Triton CST apparatus (Triton WPRL, Type 130) with a CST paper size $7 \times 9 \mathrm{~cm}$ was used for the CST measurement, while the Buchner funnel with the Whatman No. 1 qualitative filter paper $(11 \mu \mathrm{m}$ particle retention, $10 \mathrm{~cm}$ diameter $)$ and equipped with a 70 mbar vacuum suction was used for the SRF test and measurement.

\section{Results and discussion}




\section{Characterization of the two kinds of sludges}

Table 1 presents the element composition in the solid and supernatant of two kinds of sludges, i.e., alum sludge and sewerage sludge. It shows that $\mathrm{Al}$ was the dominant element in solid phase of the alum sludge apart from silicon; $\mathrm{Ca}$ and $\mathrm{Fe}$ were also presented in the solid phase of alum sludge. It can be concluded that the majority of elements (such as $\mathrm{Al}$ and $\mathrm{Fe}$ ) were in the solid phase of alum sludge, compared with the alum sludge supernatant. In sewerage sludge, Fe was the most abundant element observed in the solid phase of sewerage sludge; $\mathrm{Al}, \mathrm{Ca}, \mathrm{S}$ and $\mathrm{Si}$ were also presented. It can be seen that $\mathrm{Na}, \mathrm{Ca}, \mathrm{Fe}, \mathrm{K} \mathrm{Mg}, \mathrm{P}$ and $\mathrm{S}$ were distributed within the supernatant of sewerage sludge. Moreover, the presence of $\mathrm{P}$ both in solids and in supernatant of sewerage sludge is because the phosphorus can be released when bacteria-containing stored phosphorus (i.e., phosphate-accumulating organisms, PAOs) were subjected to anaerobic conditions, which include thickening and/or anaerobic digestion, leading to a phosphorusenriched supernatant and filtrate obtained from mechanical dewatering of the sludge; this result was in agreement with Yang et al. (2007).

Table 1 The sludge element composition in the solid phase and the supernatant

\begin{tabular}{ccccc}
\hline Elements & $\begin{array}{c}\text { Alum sludge } \\
\text { solid } \\
(\mathrm{mg} / \mathrm{kg})\end{array}$ & $\begin{array}{c}\text { Alum sludge } \\
\text { supernatant } \\
(\mathrm{mg} / \mathrm{l})\end{array}$ & $\begin{array}{c}\text { Sewerage sludge } \\
\text { solid } \\
(\mathrm{mg} / \mathrm{kg})\end{array}$ & $\begin{array}{c}\text { Sewerage sludge } \\
\text { supernatant } \\
(\mathrm{mg} / \mathrm{l})\end{array}$ \\
\hline $\mathrm{Al}$ & 7002 & $/$ & 4915 & $/$ \\
$\mathrm{Ca}$ & 1825 & 11 & 4818 & 70 \\
$\mathrm{Fe}$ & 1082 & $/$ & 28853 & 58 \\
$\mathrm{~K}$ & 1751 & 1 & $/$ & 56 \\
$\mathrm{Mg}$ & $/$ & 2 & $/$ & 12 \\
$\mathrm{Mn}$ & 1977 & $/$ & $/$ & $/$ \\
$\mathrm{Na}$ & 1541 & 4 & $/$ & 349 \\
$\mathrm{P}$ & $/$ & $/$ & 2520 & 6 \\
$\mathrm{~S}$ & 1194 & 3 & 6992 & 4 \\
$\mathrm{Si}$ & 134041 & $/$ & 7108 & 4 \\
Total & $\mathbf{1 5 0 4 1 3}$ & $\mathbf{2 1}$ & $\mathbf{5 5 2 0 6}$ & $\mathbf{5 4 8}$
\end{tabular}

The element percentage of CHNS of the two kinds of sludges is shown in Table 2. Regarding the alum sludge, carbon, nitrogen, sulfur and hydrogen only account very little percentage (less than $10 \%$ ). However, in the sewerage sludge, carbon is the overwhelming element compared 
with the other three elements, even there is very little percentage of sulfur in the sewerage sludge, which agreed with Gutiérrez Ortiz et al. (2014a, b).

Table 2 CHNS of alum sludge and sewerage sludge (\%)

\begin{tabular}{ccccc}
\hline Element (\%) & $\mathbf{C}$ & $\mathbf{H}$ & $\mathbf{N}$ & $\mathbf{S}$ \\
\hline Alum sludge & 8 & 2 & 1 & 0 \\
Sewerage sludge & 40 & 8 & 7 & 0.5 \\
\hline
\end{tabular}

The SEM-EDX data is shown in Figure 1, the solid phase texture of alum sludge and sewerage sludge as well as the elements on the surface of the two kinds of sludges was presented. Alum sludge presented a more porous surface compared with the flat surface of sewerage sludge. Regarding the result obtained from the EDX analysis, Si was the most abundant element observed on point 1 and 2 of alum sludge, point 1 of alum sludge contain more elements such as $\mathrm{Fe}, \mathrm{Mg}$ and $\mathrm{P}$ compared with point 2. It indicated that the elements were not distributed uniformly on the surface of the alum sludge. From the sewerage sludge (in Figure $1 b$ ), elements such as $\mathrm{Na}, \mathrm{Cl}, \mathrm{Cr}$, etc. were identified in addition to the once reported in Table 1. Furthermore, this morphology also indicated that alum sludge could be used as a physical conditioner or skeleton builder during the conditioning process (Qi et al. 2011a, b). 


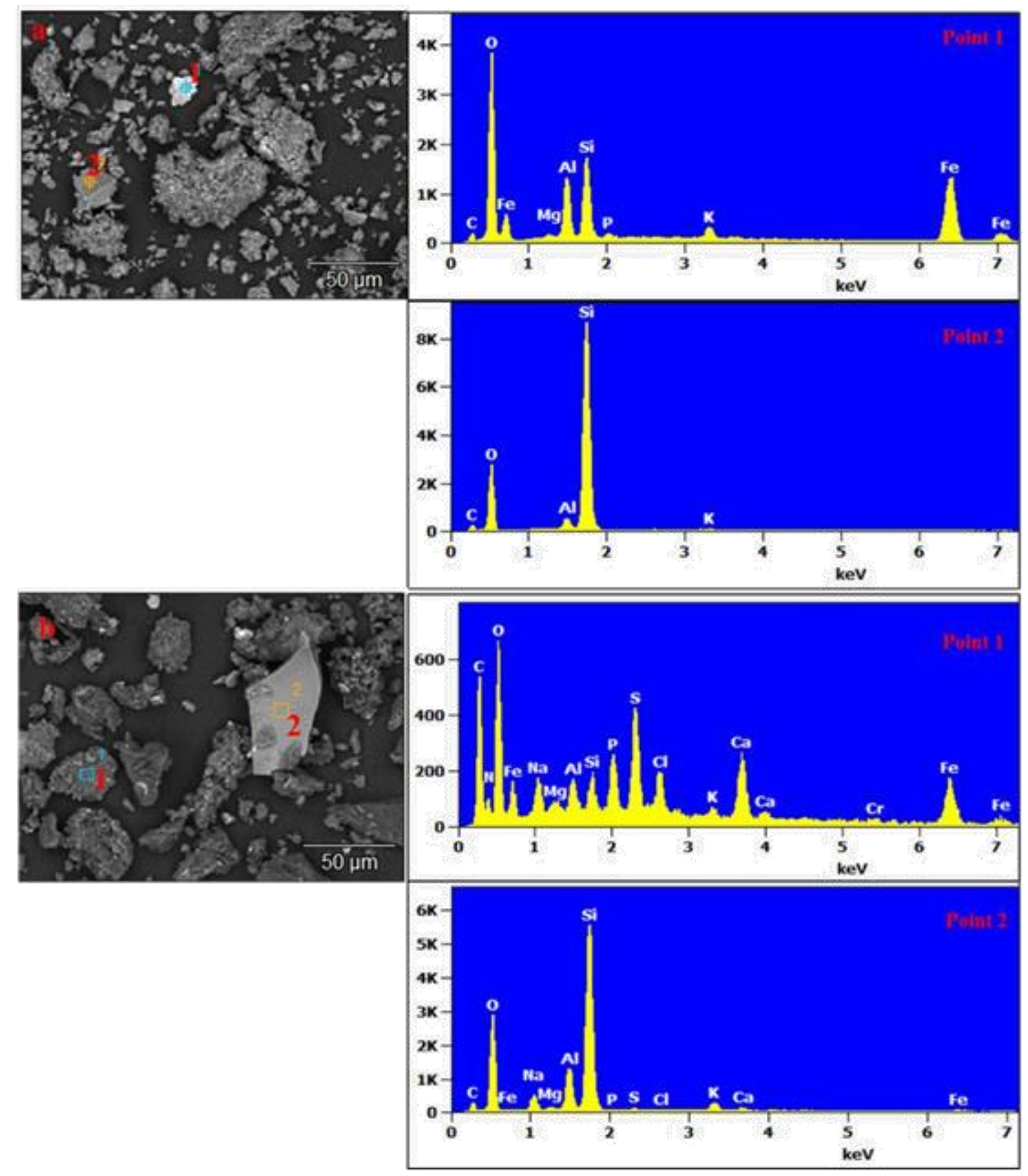

Fig. 1 SEM-EDX of (a) alum sludge and (b) sewerage sludge

\section{Optimal mixing ratio of the sludges}

The CST and SRF of the two kinds of sludges as well as the mixed sludge are jointly presented in Figure 2. It can be seen that the sewerage sludge CST and SRF were 59s and 5.5×1012 m/kg, respectively; compared with the alum sludge CST and SRF ( $3 \mathrm{~s}$ and $2.6 \times 1012 \mathrm{~m} / \mathrm{kg}$ ), the dewaterability of the sewerage sludge can be characterized as poor, as the CST and SRF of sewerage sludge was about 23 times and 18 times higher than those of alum sludge, respectively. 
To examine the effect of the introduction of alum sludge on both the sewerage sludge dewaterability and the element variation in the mixed sludge, different ratios i.e. 2:1, 1:1, 1:2, 1:3 and 1:4 (alum sludge/sewerage sludge, v/v), of the two sludges were mixed, and the CST and SRF of mixed sludge and the element composition of the mixed sludge were measured. The results are jointly shown in Figure 2 and Table 3.

As illustrated in Figure 2 (plot in blue columns), by adding the liquid alum sludge into the sewerage sludge, the CST and SRF were decreasing. It indicated that the dewaterability of the sewerage sludge improved. Moreover, the improved sewerage sludge dewaterability can be enhanced with an increasing amount of the alum sludge addition from the ratio of 1:4 to 2:1 (alum sludge:sewerage sludge, v/v). Since the SRF $(4.2 \times 1012 \mathrm{~m} / \mathrm{kg})$ and CST (50s) of the mixed ratio 1:4 were both decreased to a SRF of $2.0 \times 1012 \mathrm{~m} / \mathrm{kg}$ and a CST of $4 \mathrm{~s}$ of the mixed ratio 2:1. The mechanisms were likely driven by a large portion of insoluble aluminum hydroxides in the liquid and/or solid phase of alum sludge acting as a coagulant in coagulation/flocculation by particle-particle bridging and surface charge neutralization processes (Chu 2001). Additionally, the solid phase of alum sludge could act as the skeleton builders as well during the conditioning process (Basibuyuk and Kalat 2004). Many researchers reported similar results about using alum sludge as a chemical coagulant. Nair and Ahammed (2015) examined alum sludge usage as a coagulant for the post-treatment of up-flow anaerobic sludge blanket (UASB) reactors treating urban wastewater. Foroughi et al. (2018) reported turbidity removal in drinking water treatment using alum sludge as a coagulant agent. Mazari et al. (2018) investigated the potential reuse of alum sludge as primary coagulant in terms of membrane fouling reduction. Alum sludge can also act as a skeleton builder or filter aid (Li et al. 2016), which can effectively reduce sludge compressibility. This helps the sludge cake form a permeable and rigid structure while maintaining porosity, even under a high compression pressure. This is because its physical morphology is rigid which could act as a skeleton. 


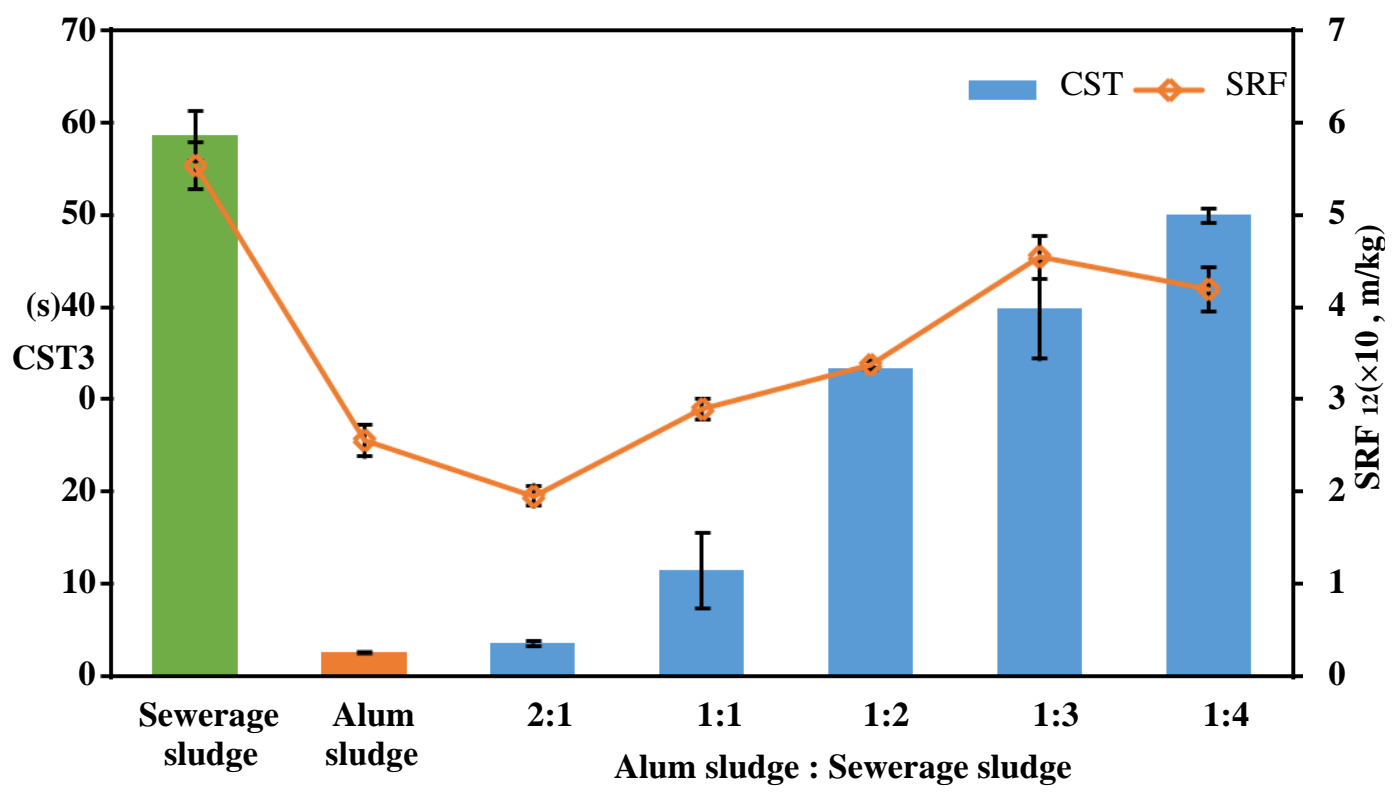

Fig. 2 CST \& SRF of two kinds of raw sludges and the mixed sludge

Table 3 shows the different elemental concentrations in supernatant of the different sludge mixing ratios. Overall, increasing the sewerage sludge ratio could result in the relevant elements rising in mixed sludge, such as $\mathrm{Al}, \mathrm{Fe}$ and $\mathrm{Na}$. This is likely because the sewerage sludge could bring various metal elements into the mixed sludge. As in Table 1, the various metal elements in the supernatant of sewerage sludge are greater than those of alum sludge. Significantly, it has been proved by Yang et al. (2009) that Al has a very strong affinity with P, due to the ligand exchange adsorption mechanisms. Therefore, the $\mathrm{P}$ concentration was decreasing from 1.8 to 0 $\mathrm{mg} / \mathrm{l}$, by mixing the liquid alum sludge with sewerage from 1:4 to 2:1 (alum sludge: sewerage sludge, v/v). However, the initial $\mathrm{P}$ concentration in the supernatant of the sewerage sludge is $6 \mathrm{mg} / \mathrm{l}$ (see Table 1). The co-conditioning process could partially remove the $\mathrm{P}$ in the supernatant, which could benefit for the biological P removal process of Graulhet WWTP. In fact, by adding the liquid alum sludge could potentially increase the overall treatment volume of the mixed sludge, which will increase the hydraulic load as well as the treatment capacity on the dewatering unit in the WWTP of Graulhet (France). Currently, the volume of sludge thickening tank is $400 \mathrm{~m} 3$, which was over designed. Thus, by considering the $\mathrm{P}$ concentration in the supernatant as well as the sludge treatment capacity of WWTP in Graulhet, the optimal mix ratio was chosen as 1:1 for the following sludge conditioning tests by adding the polymer as a conditioner. 
Table 3 The elements in supernatant under different mix ratio (alum sludge:sewerage sludge)

\begin{tabular}{ccccccc}
\hline $\begin{array}{c}\text { Elements } \\
(\mathbf{m g} / \mathbf{l})\end{array}$ & $\mathbf{2 : 1}$ & $\mathbf{1 : 1}$ & $\mathbf{1 : 2}$ & $\mathbf{1 : 3}$ & $\mathbf{1 : 4}$ & $\begin{array}{c}\text { Variation } \\
\text { (2:1 to 1:4) }\end{array}$ \\
\hline $\mathrm{Al}$ & $/$ & 3.7 & 19.3 & 15.7 & 13.9 & 13.9 \\
$\mathrm{Ca}$ & 43.7 & 20.2 & 35.2 & 44.0 & 46.9 & 3.2 \\
$\mathrm{Cr}$ & $/$ & $/$ & 0.3 & 0.3 & 0.4 & 0.4 \\
$\mathrm{Fe}$ & 1.5 & 1.7 & 6.5 & 13.1 & 14.3 & 12.8 \\
$\mathrm{~K}$ & 22.5 & 45.7 & 95.1 & 103.0 & 93.4 & 70.9 \\
$\mathrm{Mg}$ & 7.4 & 4.5 & 7.4 & 9.4 & 9.7 & 2.3 \\
$\mathrm{Mn}$ & 3.0 & 0.3 & 0.4 & 0.5 & 0.4 & -2.6 \\
$\mathrm{Na}$ & 176.5 & 370.2 & 614.4 & 654.0 & 569.0 & 392.5 \\
$\mathrm{P}$ & $/$ & 0.4 & 1.7 & 2.4 & 1.8 & 1.8 \\
$\mathrm{~S}$ & 3.7 & 4.2 & 10.8 & 10.9 & 13.8 & 10.1 \\
$\mathrm{Si}$ & 2.1 & 2.0 & 4.3 & 4.7 & 5.0 & 2.9 \\
\hline
\end{tabular}

\section{Polymer conditioning of the mixed sludge}

As above, the optimal 1:1 mix ratio was determined that ensures the lowest mixed sludge CST and SRF as well as the phosphate concentration in the supernatant with the least amount of alum sludge addition. However, as a chemical conditioner, organic polymer has been widely used in sludge treatment practice to significantly improve the sludge dewaterability. It is believed that the addition of polymer in optimal mixed sludge could further improve the sludge dewaterability but with an obviously reduced dosage (compared with the sewerage sludge conditioning). The dewatering ability (evaluated by CST and SRF) of the optimal mixed ratio $(1: 1)$ by adding a cationic polyacrylamide Superfloc-492HMW (dosage range from 10 to 400 $\mathrm{mg} / \mathrm{l}$ ) is jointly presented in Figure 3. It can be seen that SRF and CST decreased from $2.9 \times 1012$ to $1.4 \times 1012 \mathrm{~m} / \mathrm{kg}$ and from 5 to $2 \mathrm{~s}$, respectively, when the polymer dosage increased from 10 to $200 \mathrm{mg} / \mathrm{L}$. Thereafter, the SRF and CST were continuously rising by increasing the polymer dosage. It indicated that a further increase of polymer dosage did not bring about any further decrease of SRF and/or CST. Thus, the optimal polymer dosage for the mixed sludge was determined to be $200 \mathrm{mg} / \mathrm{L}$ (the turning point). 
In summary, adding the liquid alum sludge into sewerage sludge could result in an easily dewatering mixed sludge, as the lower SRF and CST were achieved. Moreover, it has been proved that a continuous reduction of SRF and CST can be achieved by adding a very little amount of polymer (200 mg/L) into the mixed sludge. Significantly, the polymer (Superfloc492HMW) dosage under the current treatment capacity of Graulhet WWTP is $2.8 \mathrm{~g} / \mathrm{L}$ (CST and SRF are $12 \mathrm{~s}$ and $3.6 \times 1012 \mathrm{~m} / \mathrm{kg}$, respectively), while the mixed sludge only needs a 200 mg/L polymer dosage. In fact, this result also agrees with Lai and Liu (2004); they have shown a decrease in the cationic polyelectrolyte when alum sludge was co-conditioned with an activated sludge. Additionally, it has been investigated by Yang et al., (2009) that the alum sludge could act as a skeleton builder, making the mixed sludge more incompressible and making the dewatering process more effective.

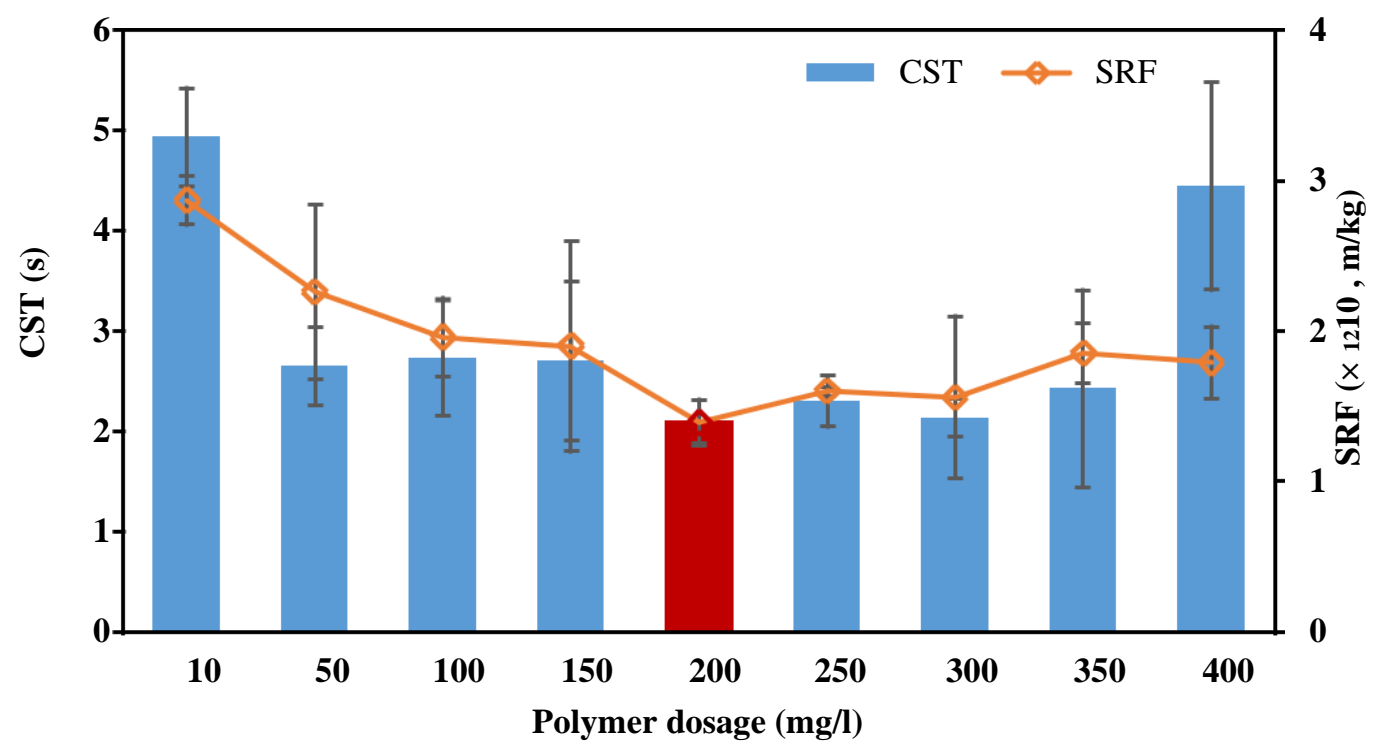

Fig. 3 The optimum polymer dosage of at mix ratio 1:1

\section{Case analysis}

The process illustrated in Figure 4 details the proposed integration of the alum sludge in coconditioning and dewatering with waste-activated sludge. Specifically, the waterworks of Graulhet is just located $3 \mathrm{~km}$ from the Graulhet WWTP and operated by the same company, thus it may be practical to build a drain pipe from the waterworks to the Graulhet WWTP. Considering the sludge production balance in these two sources, the maximum liquid alum sludge generation rate of the waterworks is $66 \mathrm{~m} 3 /$ day ( $3 \%$ of the raw water volume) while the design compacity of sewerage sludge thickening tank in Grauhet WWTP is $400 \mathrm{~m} 3$. Thus, a 
steel tank is needed to store the alum sludge. Table 4 summarizes the main pipe materials and estimated costs with the pipe manufacturing, tank construction, and electricity needed. The unit prices are based on Herstein and Filion (2011). The flow velocity of liquid alum sludge in the cement-mortar-lined ductile iron pipe was estimated at $1.0 \mathrm{~m} / \mathrm{s}$; thus, at the diameter of $100 \mathrm{~mm}$ pipe could fulfill the requirement. The prices of commercially-available steel tank was based on a French steel supplier. The horizontal multistage centrifugal pump was estimated with a 70 m pump head, while the price is from "2016 price list of Salmson Warehouse, Laval, France". It can be seen that 418,577 Euro should be invested for the co-conditioning strategy.

Table 4 The main materials and costs of initial investment

\begin{tabular}{|c|c|c|c|c|}
\hline Materials & $\begin{array}{c}\text { Unit Prices } \\
(€)\end{array}$ & Specification & Costs (€) & Reference \\
\hline $\begin{array}{l}\text { Cement-mortar-lined } \\
\text { ductile iron pipe }\end{array}$ & 50 & $3000(\mathrm{~m})$ & 150,000 & $\begin{array}{l}\text { (Herstein and } \\
\text { Filion 2011) }\end{array}$ \\
\hline $\begin{array}{c}\text { Commercially-available } \\
\text { steel tank }\end{array}$ & l & $450\left(\mathrm{~m}^{3}\right)$ & 265,000 & $\begin{array}{c}\text { A France steel } \\
\text { supplier }\end{array}$ \\
\hline $\begin{array}{l}\text { Horizontal multistage } \\
\text { centrifugal pump }\end{array}$ & 3577 & MULTI-H1600 & 3,577 & $\begin{array}{c}\text { "2016 price list } \\
\text { of Salmson } \\
\text { Warehouse, } \\
\text { Laval, France" }\end{array}$ \\
\hline In Total & - & - & 418,577 & - \\
\hline
\end{tabular}

Regarding the co-conditioning process, currently Graulhet WWTP could consume $25 \mathrm{~kg}$ polymer per day. However, if the strategy of co-conditioning with liquid alum sludge was applied, the annual polymer saving could be $8473 \mathrm{~kg}$. Currently, the price of polymer (from a local supplier in France) is 5.24 Euro/kg (including tax); the polymer saving could equal 44,399 Euro per year, accounting for $93 \%$ of the current annual polymer costs. On the other hand, the potential increases of sludge cakes will be from 25,000 to $25,321 \mathrm{~kg} /$ day when liquid alum sludge is introduced. Accordingly, the relevant sludge disposal cost will be rising to approximately 7100 Euro per year (considering the average sludge disposal fee of 65 Euro/ton (Zhao et al. 2016)).

Although extra capital investment and construction cost are estimated at 418,577 Euro, as well as the extra sludge disposal fee of approximately 7,100 Euro/year, the polymer savings benefits of 44,399 Euro/year can be achieved, which means the initial investment and operational expenses could be returned by polymer saving in 11 years. It seems a long time. But compared with the long-term effect for the local "circular economy", it is a relatively short 
period. Significantly, the sustainable sludge management route should be prioritized since the legislation is not allowed the liquid alum sludge from the waterworks drainage to the river anymore. In addition, in spite of the increased quantity of the reject water from dewatering unit, the significant reduction of $\mathrm{P}$ in reject water could benefit the wastewater treatment process regarding $\mathrm{P}$ loading. Overall, from a technical point-of-view, the co-conditioning and dewatering strategy is practicable, and the cost-effective analysis also demonstrated that the initial investment fee could be returned.

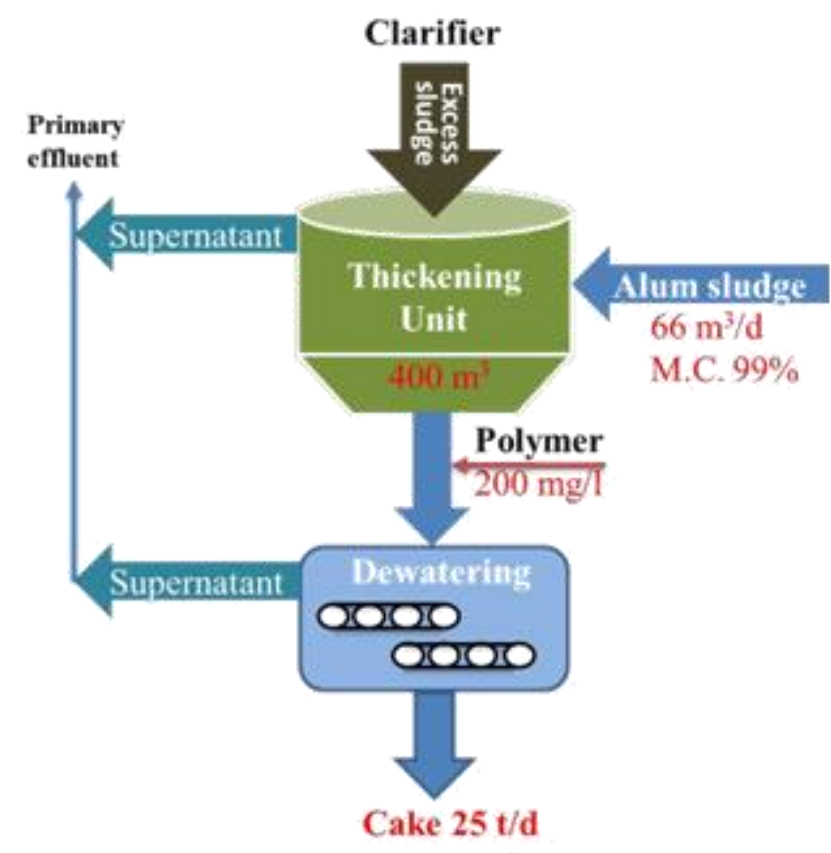

Fig. 4 Schematic of a proposed strategy of alum sludge co-conditioning with the waste activated sludge of Graulhet WWTP

\section{Conclusions}

The liquid alum sludge obtained from Graulhet (France) WTP can be used to co-conditioning and dewatering with the sewerage sludge from WWTP, since the addition of liquid alum sludge to the waste-activated sludge could improve its dewaterability. By considering the $\mathrm{P}$ concentration in the supernatant as well as the treatment capacity of Graulhet WWTP, the optimal mixing ratio is 1:1 (sewerage sludge:alum sludge, v/v). Moreover, the optimal polymer (Superfloc-492HMW) dosage for the mixed sludge ratio (1:1) was $200 \mathrm{mg} / \mathrm{l}$, while the current dosage for the waste-activated sludge in Graulhet WWTP is $2.8 \mathrm{~g} / 1$. An integrated cost-effective evaluation of process capabilities, sludge transport, and increased cake disposal, additional 
administration, etc. suggests that the co-conditioning and dewatering strategy for Graulhet water industry is practicable, theoretically the initial investment could be returned in 11 years. Therefore, a scientific investigation but also a "Circular Economy" approach was provided for Graulhet (France) water industry.

\section{Acknowledgements}

The first author greatly acknowledges the $\mathrm{PhD}$ scholarship received jointly from University College Dublin, Ireland and China Scholarship Council (CSC). The RAPSODEE research centre (CNRS UMR 5302), France as well as the staff in Régie Municipale de l'Eaux et de l'Assainissement de Graulhet were also gratefully acknowledged for the technological support.

\section{References}

Ahmad, T., Ahmad, K. and Alam, M. (2016) Sustainable management of water treatment sludge through 3'R' concept. Journal of Cleaner Production 124(Supplement C): 1-13.

Basibuyuk, M. and Kalat, D.G. (2004) The use of waterworks sludge for the treatment of vegetable oil refinery industry wastewater. Environmental Technology 25(3): 373-380.

Bi, D.S., Guo, X.P., Cai, Z.H., Yu, Z., Wang, D.M. and Wang, Y.Q. (2015) Enhanced dewaterability of waste-activated sludge by combined cationic polyacrylamide and magnetic field pretreatment. Environmental Technology 36(4): 455-462.

Chang, G.R., Liu, J.C. and Lee, D.J. (2001) Co-conditioning and dewatering of chemical sludge and waste activated sludge. Water Research 35(3): 786-794.

Chu, W. (2001) Dye Removal from Textile Dye Wastewater Using Recycled Alum Sludge. Water Research 35(13): 3147-3152.

Foroughi, M., Chavoshi, S., Bagheri, M., Yetilmezsoy, K. and Samadi, M.T. (2018) Alumbased sludge $(\mathrm{AbS})$ recycling for turbidity removal in drinking water treatment: an insight into statistical, technical, and health-related standpoints. Journal of Material Cycles and Waste Management 20(4): 1999-2017.

Guo, J., Chen, C., Jiang, S. and Zhou, Y. (2018) Feasibility and Mechanism of Combined Conditioning with Coagulant and Flocculant To Enhance Sludge Dewatering. ACS Sustainable Chemistry \& Engineering 6(8): 10758-10765. 
Gutiérrez Ortiz, F.J., Aguilera, P.G. and Ollero, P. (2014a) Biogas desulfurization by adsorption on thermally treated sewage-sludge. Separation and Purification Technology 123: 200-213.

Gutiérrez Ortiz, F.J., Aguilera, P.G. and Ollero, P. (2014b) Modeling and simulation of the adsorption of biogas hydrogen sulfide on treated sewage-sludge. Chemical Engineering Journal 253: 305-315.

Herstein, L.M. and Filion, Y.R. (2011) Life-cycle assessment of common water main materials in water distribution networks. Journal of Hydroinformatics 13(3): 346-357.

Lai, J.Y. and Liu, J.C. (2004) Co-conditioning and dewatering of alum sludge and waste activated sludge. Water Science and Technology 50(9): 41-48.

Li, J., Liu, L., Liu, J., Ma, T., Yan, A. and Ni, Y. (2016) Effect of adding alum sludge from water treatment plant on sewage sludge dewatering. Journal of Environmental Chemical Engineering 4(1): 746-752.

Mazari, L., Abdessemed, D. and Szymczyk, A. (2018) Evaluating Reuse of Alum Sludge as Coagulant for Tertiary Wastewater Treatment. Journal of Environmental Engineering 144(12): 04018119.

Nair, A.T. and Ahammed, M.M. (2015) The reuse of water treatment sludge as a coagulant for post-treatment of UASB reactor treating urban wastewater. Journal of Cleaner Production 96: 272-281.

Pambou, Y.B., Fraikin, L., Salmon, T., Crine, M. and Leonard, A. (2016) Enhanced sludge dewatering and drying comparison of two linear polyelectrolytes co-conditioning with polyaluminum chloride. Desalination and Water Treatment 57(58): 27989-28006.

Qi, Y., Thapa, K.B. and Hoadley, A.F.A. (2011a) Application of filtration aids for improving sludge dewatering properties - A review. Chemical Engineering Journal 171(2): 373-384.

Qi, Y., Thapa, K.B. and Hoadley, A.F.A. (2011b) Benefit of lignite as a filter aid for dewatering of digested sewage sludge demonstrated in pilot scale trials. Chemical Engineering Journal 166(2): 504-510.

Ren, B., Zhao, Y., Lyczko, N. and Nzihou, A. (2019) Current Status and Outlook of Odor Removal Technologies in Wastewater Treatment Plant. Waste and Biomass Valorization 10(6): 1443-1458.

Wang, Y., Ren, B.M., Zhao, Y.Q., English, A. and Cannon, M. (2018) A comparison of alum sludge with peat for aqueous glyphosate removal for maximizing their value for practical use. Water Science and Technology 2017(2): 450-456. 
Wei, H., Gao, B., Ren, J., Li, A. and Yang, H. (2018) Coagulation/flocculation in dewatering of sludge: A review. Water Research 143: 608-631.

Xiong, Q., Zhou, M., Yang, H., Liu, M., Wang, T., Dong, Y. and Hou, H. (2018) Improving the Dewaterability of Sewage Sludge Using Rice Husk and Fe2+-Sodium Persulfate Oxidation. ACS Sustainable Chemistry \& Engineering 6(1): 872-881.

Yang, Y., Zhao, Y.Q., Babatunde, A.O. and Kearney, P. (2007) Co-conditioning of the anaerobic digested sludge of a municipal wastewater treatment plant with alum sludge: Benefit of phosphorus reduction in reject water. Water Environment Research 79(13): 24682476.

Yang, Y., Zhao, Y.Q., Babatunde, A.O. and Kearney, P. (2009) Two strategies for phosphorus removal from reject water of municipal wastewater treatment plant using alum sludge. Water Science and Technology 60(12): 3181-3188.

Yang, Y., Zhao, Y.Q., Liu, R.B. and Morgan, D. (2018) Global development of various emerged substrates utilized in constructed wetlands. Bioresource Technology 261: 441-452.

Zhao, Y., Liu, R., Awe, O.W., Yang, Y. and Shen, C. (2018) Acceptability of land application of alum-based water treatment residuals - An explicit and comprehensive review. Chemical Engineering Journal 353: 717-726.

Zhao, Y., Ren, B., O'Brien, A. and O'Toole, S. (2016) Using alum sludge for clay brick: an Irish investigation. International Journal of Environmental Studies 73(5): 719-730.

Zhu, C., Zhang, P., Wang, H. and Ye, J. (2018) Conditioning of sewage sludge via combined ultrasonication-flocculation-skeleton building to improve sludge dewaterability. Ultrasonics Sonochemistry 40: 353-360. 